\title{
Isolated and bilateral simultaneous facial palsy disclosing early human immunodeficiency virus infection
}

Pornchai Sathirapanya, MD

\begin{abstract}
Bilateral lower motor neuron type facial palsy is an unusual neurological disorder. There are few reports that associate it with the human immunodeficiency virus (HIV) infection on initial presentation. A 51-year-old married woman, who was previously healthy and had no risk of HIV infection, presented solely with bilateral simultaneous facial palsy. A positive HIV serology test was confirmed by an enzyme-linked immunosorbent assay test. Following a short course of oral prednisolone, the patient recovered completely from facial palsy in three months, even though an antiretroviral treatment was suspended. Exclusion of HIV infection in patients with bilateral facial palsy is essential for early diagnosis and management of HIV.
\end{abstract}

Keywords: facial paralysis, HIV infection, prednisolone

\section{INTRODUCTION}

Unlike Bell's palsy, bilateral facial palsy (BFP) is an uncommon cranial neuropathy. It has been associated with various aetiologies, including human immunodeficiency virus (HIV) infection, and can be its harbinger.

\section{CASE REPORT}

A 51-year-old married woman who was previously healthy suddenly developed bilateral and simultaneous lower motor neuron type facial palsy one week prior to presentation. She appeared healthy and had no fever. A general systematic examination was unremarkable and BFP was the only neurological disorder demonstrated. Enhanced computed tomography of the brain was unremarkable. Cerebrospinal fluid (CSF) analysis revealed an opening pressure of $1,323.89 \mathrm{~Pa}$, a total white blood cell count of $8 \times 10^{6}$ cells/L (all lymphocytes), red blood cell count of $10 \times 10^{6}$ cells $/ \mathrm{L}$, CSF protein of $0.89 \mathrm{~g} / \mathrm{L}$ and CSF glucose of $3.05 \mathrm{mmol} / \mathrm{L}$ (blood glucose of $7.22 \mathrm{mmol} / \mathrm{L}$ ), and no neoplastic cells. A neuro-electrophysiological test demonstrated axonopathy of both facial nerves but normal neurophysiologic results in all peripheral nerves.

An anti-HIV serologic test (enzyme-linked immunosorbent assay) yielded a positive result. Rapid plasma reagin and Treponema pallidumantibody tests were both nonreactive. Serum toxoplasmosis and cryptococcal antibody tests showed negative results. The patient denied that she had been exposed to any HIV risks. Total CD4 count was $4.12 \times 10^{8}$ cells $/ \mathrm{L}$ ( $16 \%$ of total lymphocytes). Results of the patient's HIV viral load test were not available. Immune-mediated facial neuropathy related to early HIV infection was provisionally diagnosed and oral prednisolone $1 \mathrm{mg} / \mathrm{kg} /$ day was prescribed for seven days. The patient experienced complete recovery of facial muscle power at the end of the third month, although no concomitant antiretroviral therapy was initiated. 15 months after the onset of BFP, the patient remained well with an increase in total CD4 count to $4.82 \times 10^{8}$ cells/L ( $18 \%$ of total lymphocytes).

\section{DISCUSSION}

BFP represents only $0.2 \%-3 \%$ of facial paralysis cases. ${ }^{(1)}$ Common aetiologies of BFP are various infections and immune-mediated disorders, including herpes simplex type 1 virus (HSV-1), EpsteinBarr virus, Borrelia burgdorferi, Guillain-Barré syndrome (GBS) ${ }^{(2)}$ and sarcoidosis. ${ }^{(3)}$ However, facial palsy associated with HIV infection has rarely been reported; ${ }^{(4)}$ only $0.9 \%$ of BFP patients revealed HIV infection. ${ }^{(5)}$ The development of either unilateral or bilateral facial palsy at any point during the course of HIV infection was found to be related to host immune status. ${ }^{(6)}$ During seroconversion, a wide range of neurological disorders were reported, including cranial neuropathy, and most cases involved facial neuropathy ${ }^{(7)}$ In contrast, opportunistic infections of the nervous system and neoplasms such as HSV-1, herpes zoster, tuberculous or cryptococcal meningitis and lymphomatous meningitis were commonly associated with advanced HIV infection. ${ }^{(4,8)}$

Evidence is inconclusive on the optimal treatment for BFP in HIV-infected patients. A short course of oral prednisolone has been advocated by some authors. ${ }^{(9)}$ Similar to cases of Bell's palsy, most BFP cases occurring during the seroconversion phase of HIV infection had a satisfactory response to oral prednisolone. Spontaneous complete recovery has also been observed. ${ }^{(10,11)}$ However, studies have not confirmed the benefit of antiretroviral therapy.

This patient reported herein had no prior HIV risks and may have acquired the infection from heterosexual sexual contact. Her neurological presentation was rare, as the BFP was simultaneous and occurred without other associated symptoms. There was no prodrome of systemic viral infection or aseptic meningitis, which were reported in previous studies. ${ }^{(4,10,12-14)}$ The patient's CSF profiles were similar to those usually found in GBS; however, the electrophysiological results did not fit the diagnosis of classical GBS. Therefore, a cranial neuropathy variant of GBS might be possible. 
In conclusion, bilateral facial neuropathy frequently indicates catastrophic aetiologies that require further investigations, as systemic infections and immunological disorders are often involved. Early diagnosis and management of these disorders is medically crucial.

\section{REFERENCES}

1. Sherwen PJ, Thong NC. Bilateral facial nerve palsy: a case study and literature review. J Otolaryngol 1987; 16:28-33.

2. Pothiawala S, Lateef F. Bilateral facial nerve palsy: a diagnostic dilemma. Case Rep Emerg Med 2012; 2012:458371.

3. Jain V, Deshmukh A, Gollomp S. Bilateral facial paralysis: case presentation and discussion of differential diagnosis. J Gen Intern Med 2006; 21:C7-10.

4. Abboud O, Saliba I. Isolated bilateral facial paralysis revealing AIDS: a unique presentation. Laryngoscope 2008; 118:580-4.

5. Teller DC, Murphy TP. Bilateral facial paralysis: a case presentation and literature review. J Otolaryngol 1992; 21:44-7.

6. Kohler A, Burkhard P, Magistris MR, Chofflon M. [lsolated peripheral facia paralysis and HIV infection: 7 cases]. Rev Neurol (Paris) 1995; 151:332-7. French.
7. Kassutto S, Rosenberg ES. Primary HIV type 1 infection. Clin Infect Dis 2004; 38:1447-53.

8. Sasaki Md, Leite PG, Leite AG, de Almeida SM. Bilateral peripheral facial palsy secondary to lymphoma in a patient with HIV/AIDS: a case report and literature review. Braz J Infect Dis 2002; 6:50-4.

9. Pletcher SD, Goldberg AN. Head and neck manifestations of human immunodeficiency virus infection. In: Cummings CW, Flint PW, Haughey $\mathrm{BH}$, et al, eds. Cummings otolaryngology: head and neck surgery [e-book]. 4th ed. Philadelphia: Mosby, 2005. Available at: http:// home.md.com/consult.com/das/book/64456967-2/view/1263. Accessed November 25, 2006.

10. Yeo JC, Trotter MI, Wilson F. Bilateral facial nerve palsy associated with HIV seroconversion illness. Postgrad Med J 2008; 84:328-9.

11. Serrano P, Hernández N, Arroyo JA, de Llobet JM, Domingo P. Bilateral Bell palsy and acute HIV type 1 infection: report of 2 cases and review. Clin Infect Dis 2007; 44:e57-61.

12. Kim MS, Yoon HJ, Kim HJ, et al. Bilateral peripheral facial palsy in a patient with Human Immunodeficiency Virus (HIV) infection. Yonsei Med J 2006; 47:745-7.

13. Krasner CG, Cohen SH. Bilateral Bell's palsy and aseptic meningitis in a patient with acute human immunodeficiency virus seroconversion. West J Med 1993; 159:604-5.

14. Ruiz LM, Kirmani B. Presentation of Bilateral Peripheral Seventh Cranial Nerve Palsy in an HIV patient. Case Rep Neurol Med 2012; 2012:267405. 